\title{
Human-Induced Vibration Control with TMDs for Guangzhou Asian Games Comprehensive Museum
}

\author{
Xue-Jun Yin \\ GERB (Qingdao) Vibration Control Co., Ltd., Qingdao 266108, China. \\ Zhao-Dong Xu and Yang Yang \\ Civil Engineering School, Southeast University, Nanjing 210096, China. \\ Yong Luo and Jian-Li Wang \\ GERB (Qingdao) Vibration Control Co., Ltd., Qingdao 266108, China.
}

\begin{abstract}
(Received 21 November 2017; accepted 23 July 2018)
Guangzhou Asian Games Comprehensive Museum is one of the permanent buildings for the 2010 Guangzhou Asian Games, whose bowl-shaped main body is a steel structure with the largest cantilever length of more than 30 meters. The structure has a low natural frequency, so it tends to be excited by people synchronizing walking with amplification of resonance, which will affect the serviceability. A large amount of analysis and field-tests are performed for this historical museum with tuned mass dampers (TMDs) being used to reduce human walking induced vibration. The results showed that TMDs can control the structure vertical vibration effectively, with the efficiency of over $50 \%$. The research results have obvious significance for similar projects.
\end{abstract}

\section{INTRODUCTION}

Long-span structures and high-rise structures have a low natural frequency, so these constructions tend to be excited by people synchronizing walking with amplification of resonance, which will affect the serviceability and the safety of the structure. Human-induced vibration problems include three aspects: the walking excitation load, the evaluation criterion of serviceability and the vibration control. The dynamic loading caused by people synchronizing walking is complicated, which generates forces in three directions, the vertical, horizontal and longitudinal. The typical frequency ranges of people in various activities are revealed: walking at 1.6 to $2.4 \mathrm{~Hz}$, running at 2.0 to $3.5 \mathrm{~Hz}$, jumping at 1.8 to $3.4 \mathrm{~Hz}$, and bouncing at 1.5 to $3.0 \mathrm{~Hz}$, by statistics and distributions of stride frequency done by scholars from several countries. ${ }^{1-4}$ The forces in three directions generated by people in different activities can be expressed in the form of Fourier series, and the harmonic components of at most the first five orders are usually considered in practical application. ${ }^{1-4}$

In terms of the evaluation criterion of serviceability, the acceleration is usually used as the indicator for its convenience of being measured. The evaluation of human vibration serviceability is a complex problem, because different people react differently to the same vibration and the same person reacts differently to the same vibration under different conditions. Although quite a bit of research has been done by scholars from different countries, a consistent and definitive conclusion cannot be reached. The indicators used in standards of different countries are different. ${ }^{5-11}$

The measures to control human-induced vibrations are various, in which installing dampers is a cost-effective way. Compared with simply increasing the stiffness of structures or varying the mass distribution, dampers are set without too many changes to the original structure. ${ }^{12,13}$ The common dampers used in vibration control are AMD (active mass damper) and TMD (tuned mass damper). TMD is widely used in vibration control of long-span structures for its economics and simplicity. TMD consists of masses, springs and damping systems, whose working principle is to adjust its vibration frequency to near the natural frequency of the main structure, and to change the structural resonance characteristics, in order to achieve the damping effect. ${ }^{14-18}$

The bowl of Guangzhou Asian Games Comprehensive Museum is a steel structure with the largest cantilever length of more than 30 meters. The vertical vibration frequencies of the structure are very intensive and cover the frequency range of people normally walking, so the influx of a large number of people may cause serviceability problems. TMDs were used to reduce human-induced vibration for this historical museum.

\section{THEORY}

\subsection{Building Aspects}

The real shot of the Guangzhou Asian Games Comprehensive Museum is shown in Figure 1. The usable area during the Guangzhou Asian Games is $3677 \mathrm{~m}^{2}$, the plan view size is $56 \mathrm{~m} \times 35 \mathrm{~m}$, and the roof height is $25.8 \mathrm{~m}$. The museum consists of the exhibition room under the audience platform, spiral ramp exhibition room and the roof connector of two buildings. As shown in Figure 1, the bowl is a cantilever structure, with the largest cantilever length of $33 \mathrm{~m}$. The bowl is supported on the core tube, whose plan view size is $8 \mathrm{~m} \times 6.6 \mathrm{~m}$.

Because of the long cantilever, the bowl of the structure has a low natural frequency, which is lower than $3 \mathrm{~Hz}$. According to the Technical specifications of urban pedestrian overcrossing and underpass, ${ }^{19}$ the natural frequency of the structure should be controlled under $3 \mathrm{~Hz}$, in order to keep away from the human walking frequency $(1.6 \sim 2.4 \mathrm{~Hz})$. Thus, measures 


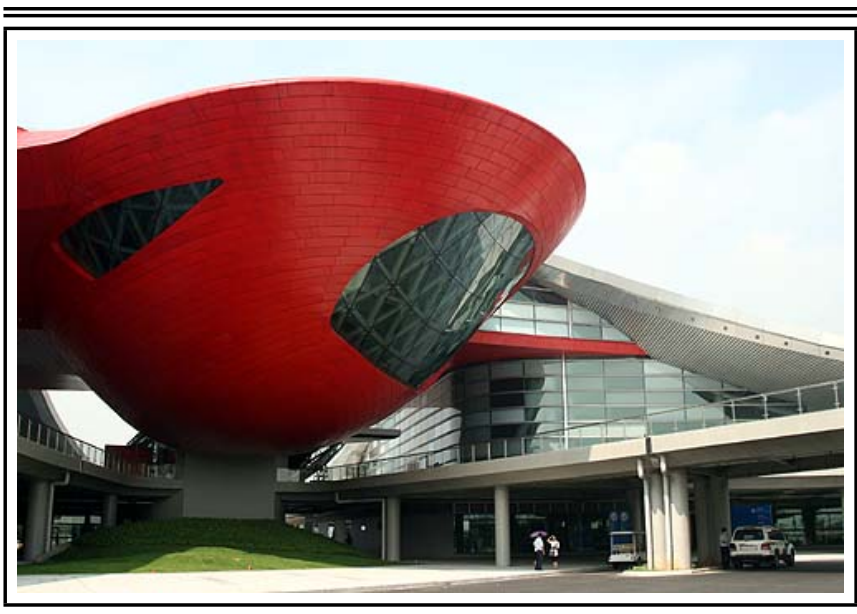

Figure 1. Guangzhou Asian Games Historical Museum.

need to be taken to keep the natural frequency of the bowl out of the human walking frequency range. For an existing building, TMD is suitable to change the structural resonance characteristics. The human-walking vibration can be attenuated by installing TMDs, without adjustments to the structure.

\subsection{Operating Principles of TMD}

As stated above, the structure has a low natural frequency, so it tends to be excited by people synchronizing walking, which will affect the serviceability. The potential serviceability problems require the TMDs to be installed for vibration control.

TMD is a typical dynamic vibration absorber, which consists of the stiffness, dampers and the mass. Its principle of vibration suppression lies in that the self-vibration frequency of the TMD is adjusted to near the natural frequency of the structure, so that the vibration of the structure will lead to the resonance of the TMD. The inertia force of the TMD reacts on the structure, which can lessen the structural vibration response. TMD has been successfully applied to high-rise buildings for wind-induced response control. ${ }^{20}$ Numerical studies have shown that TMD can also effectively reduce the vertical vibration of long-span structures.

To maximize the damping effect of TMD, the frequency of TMD shall be set near the free vibration frequency of the structure to be controlled, and the proper damping need be chosen. However, TMD has its limits. The damping effect of TMD is very sensitive to the fluctuations of the free vibration frequency, and there are always discrepancies between the actual free vibration frequencies of the structure and the calculated ones. ${ }^{21}$ More importantly, for long-span structures, the modes are intensive, which brings difficulty for a single TMD to control all these modes. Given these characteristics, Clark (1988) proposed the concept of MTMD, which aims at a certain range of frequencies to be controlled, resolving the TMD system of a certain frequency bandwidth into multiple sub-TMD systems to improve the stability of the control system. ${ }^{22}$

With MTMD attached, the dynamic equations of the multidegree of freedom system under human-walking load was:

$$
[M]\{\ddot{X}\}+[C]\{\dot{X}\}+[K]\{X\}=F ;
$$

where $[M]=\left[\begin{array}{cc}M_{S} & 0 \\ E^{T} M_{d} & M_{d}\end{array}\right],[C]=\left[\begin{array}{cc}C_{S} & -E C_{d} \\ 0 & C_{d}\end{array}\right],[K]=$ $\left[\begin{array}{cc}K_{S} & -E K_{d} \\ 0 & K_{d}\end{array}\right],[X]=\left\{\begin{array}{c}X_{d} \\ X_{S}\end{array}\right\},[F]=\left\{\begin{array}{c}f(t) \\ 0\end{array}\right\}$.
Table 1. The crowd density at different paces.

\begin{tabular}{|c|c|c|}
\hline Pace $(\mathrm{Hz})$ & Stride $(\mathrm{m})$ & Number of people $(/ \mathrm{m})$ \\
\hline 1.6 & 0.6 & 1.8 \\
\hline 1.8 & 0.7 & 1.6 \\
\hline 2.0 & 0.8 & 1.4 \\
\hline 2.2 & 0.9 & 1.2 \\
\hline 2.4 & 1.0 & 1 \\
\hline
\end{tabular}

$M_{S}, C_{S}$ and $K_{S}$ denoted the mass, damping and the stiffness matrices of the main structure, respectively. $M_{d}, C_{d}$ and $K_{d}$ denoted the mass, damping and the stiffness matrices of the TMD system. $x_{d}$ stands for the displacement vector of each TMD relative to the main structure, only with the vertical component, while the horizontal componentswere zero. $E$ is the acting position matrix of TMD. $f t$ was the time history of the walking load, which was obtained by the standard of IABSE.

It can be seen from equation (1) that, TMD contributed to the damping matrix of the structure, which showed that it can enhance the energy dissipation capacity of the main structure.

\section{METHODOLOGY}

The finite element software midas Gen was used to analyse this comprehensive museum with and without TMDs. The beam-plate 3-dimensional finite element model was used to simulate the structure components. The non-structural components and loads with mass effect were taken into the finite element model by the way of additional mass.

Use the characteristic load value and discount the live load equivalent mass with the discount factor as 0.2 . The structure damping ratio was set to 0.02 .

The outermost node of the bowl cantilever and the node at the curve of upper layer corridor were chosen as the two control nodes.

\subsection{Load Model and the Serviceability Standard}

A periodic force $F(t)$ was represented by a Fourier series, ${ }^{3}$

$$
F(t)=G\left[1+\sum_{i=1}^{3} \alpha_{i} \sin \left(2 i \pi f_{S} t-\Phi_{i}\right]\right.
$$

where $G$ was the person's weight $(\mathrm{N}), \alpha_{i}$ was the Fourier's coefficient of the $i$ th harmonic, $f_{S}$ was the step frequency of people walking.

As stated above, the typical frequency range of people walking is 1.6 to $2.4 \mathrm{~Hz}$, so $1.6 \mathrm{~Hz}, 1.8 \mathrm{~Hz}, 2.0 \mathrm{~Hz}, 2.2 \mathrm{~Hz}$, and $2.4 \mathrm{~Hz}$ were chosen as the walking excitation frequency. By using the numerical model suggested by the IABSE as the single excitation model, and in order to get the stable response, the step number was set to 40 . The single continuous walking excitation time histories at $1.6 \mathrm{~Hz}$ and $2.4 \mathrm{~Hz}$ are shown in Figure 2. It can be inferred from Figure 2 that human walking load increased along with increase in the walking frequency.

The stride $x$ at different paces is shown in Table 1, and assuming that there is one person at one stride range, then the number of people per unit area $\mathrm{n}$ equals to $1 / \mathrm{x}^{11}$

The crowd load was expressed as $P s(t)=n(f) \times r \times F(t)$, where $P s(t)$ was the dynamic force per unit area, $n(f)$ was the 


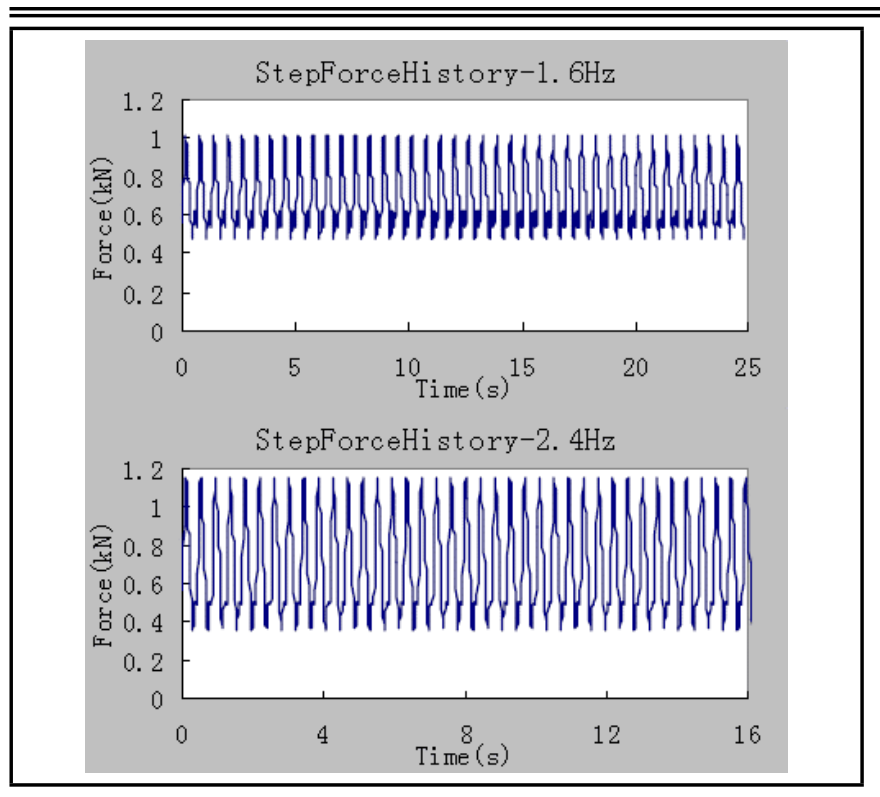

Figure 2. The single continuous walking excitation time history at: $1.6 \mathrm{~Hz}$ and $2.4 \mathrm{~Hz}$.

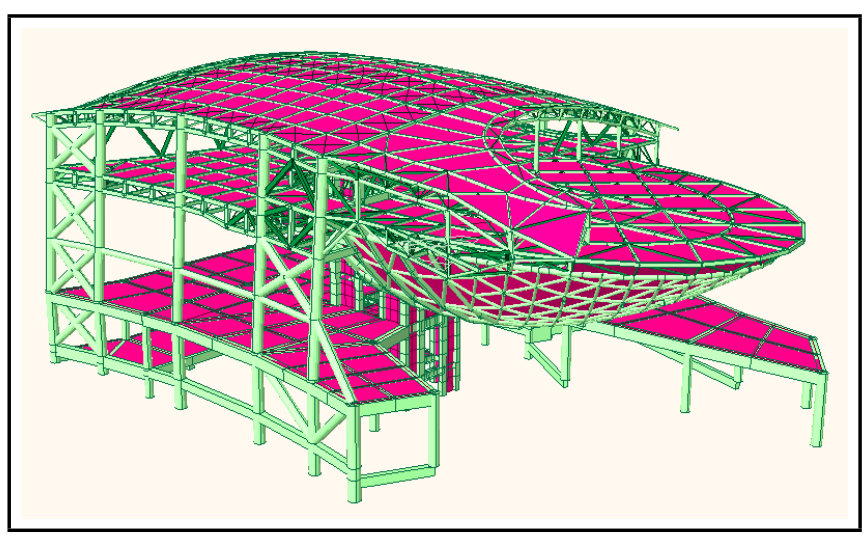

Figure 3. midas Gen computation model.

number of people per unit area related to the pace, $r$ was the synchronization percentage and $F(t)$ was the single continuous walking excitation. The synchronization percentage was set to $13.5 \% .^{2}$

The crowd load was added to the upper layer corridor (Case A), the sublayer corridor (Case B) and the bowl (Case C), in which each case contains five excitation frequencies. The 15 conditions are listed in Table 2.

The vertical vibration of the cantilever part of the structure (the bowl) and the interior corridor should meet ISO2631-2, where the vertical acceleration of interior corridor, the supermarket and the ballroom cannot exceed $0.15 \mathrm{~m} / \mathrm{s}^{2}{ }^{8}$

\subsection{Structural Modal Analysis}

In this paper, midas Gen was used to calculate the dynamic properties of this structure. The computation model is shown in Figure 3. The first 20 frequencies of structure are listed in Table 3.

As revealed in Table 3, the natural frequency of the structure was low and close to the walking excitation frequency, so the structure tends to be excited by people synchronizing walking. Table 3 shows that, the modes were so intense that a single TMD cannot achieve ideal damping effects. The first order mode of the structure is shown in Figure 4. By observing the

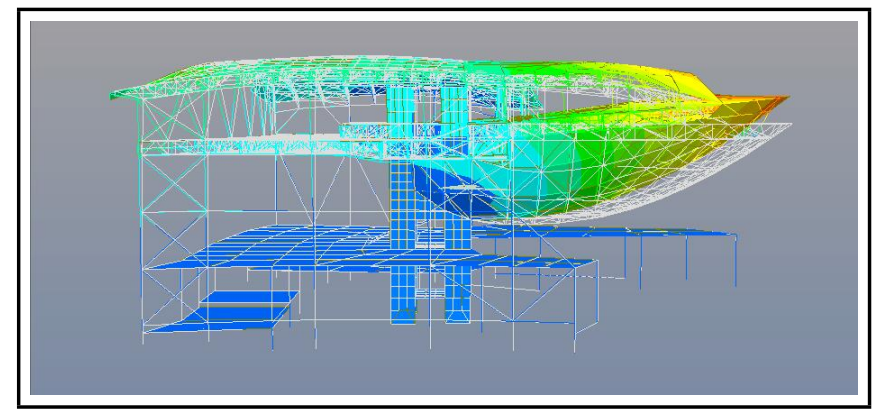

Figure 4. The first order mode of the structure.

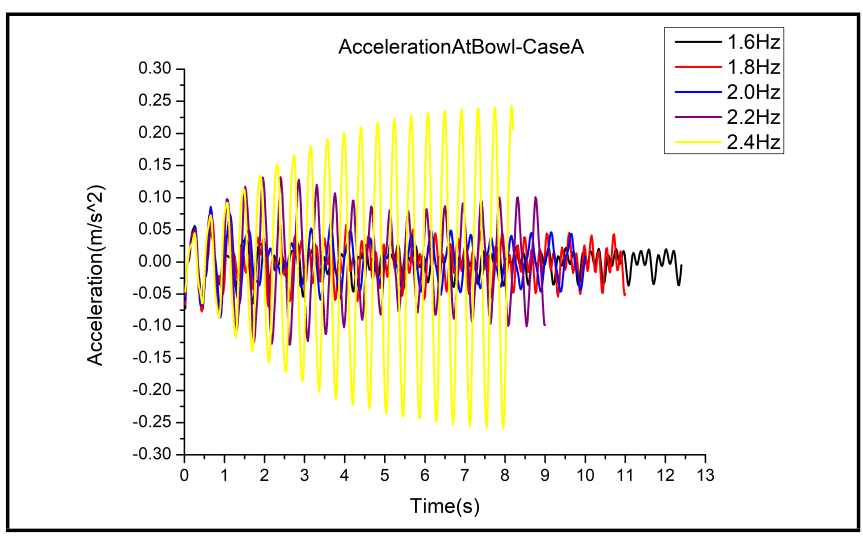

Figure 5. The acceleration response at bowl without TMD (Case A).

modal animation, it is manifested that the first mode of the structure was the vertical vibration of the bowl and the $16^{\text {th }}$, $19^{\text {th }}$ mode were the vertical vibration of the corridor.

\subsection{Dynamic Calculation of the Structure without TMD}

The structure without TMD was analysed first. The crowd load was added to the structure in the form of surface load. The acceleration responses at bowl and corridor without TMD of Case A are shown in Figure 5 and 6, respectively.

It can be seen from Figure 5 and 6, the acceleration response increases with the walking frequency. When the walking load of $2.4 \mathrm{~Hz}$ was added to the structure, the maximum acceleration was considerably larger than the limited value, which was $0.15 \mathrm{~m} / \mathrm{s}^{2}$, according to ISO2631-2. It is worth noting that an obvious resonance occurs when the crowd load of $2.4 \mathrm{~Hz}$ is added to the structure, the reason of which was that the natural frequency of the structure is $2.37 \mathrm{~Hz}$, close to the load

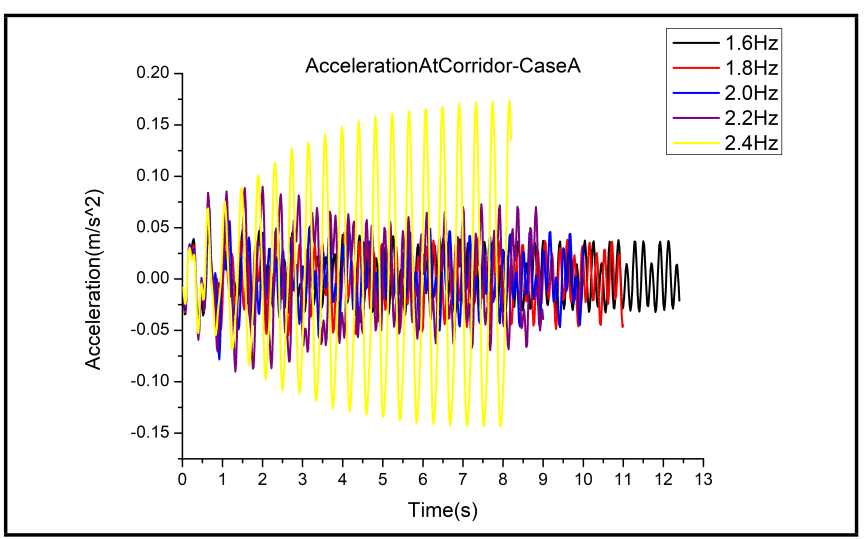

Figure 6. The acceleration response at corridor without TMD (Case A). 
Table 2. The calculation conditions.

\begin{tabular}{|c|c|c|c|c|c|c|c|c|}
\hline Condition & $\begin{array}{l}\text { Loading } \\
\text { position }\end{array}$ & $\begin{array}{l}\text { Excitation } \\
\text { frequency }\end{array}$ & Condition & $\begin{array}{l}\text { Loading } \\
\text { position }\end{array}$ & $\begin{array}{l}\text { Excitation } \\
\text { frequency }\end{array}$ & Condition & $\begin{array}{l}\text { Loading } \\
\text { position }\end{array}$ & $\begin{array}{l}\text { Excitation } \\
\text { frequency }\end{array}$ \\
\hline A. 1 & \multirow{5}{*}{ The bowl } & $1.6 \mathrm{~Hz}$ & B.1 & \multirow{5}{*}{$\begin{array}{l}\text { The upper } \\
\text { layer corridor }\end{array}$} & $1.6 \mathrm{~Hz}$ & C. 1 & \multirow{5}{*}{ The sublayer corridor } & $1.6 \mathrm{~Hz}$ \\
\hline A. 2 & & $1.8 \mathrm{~Hz}$ & B. 2 & & $1.8 \mathrm{~Hz}$ & C. 2 & & $1.8 \mathrm{~Hz}$ \\
\hline A. 3 & & $2.0 \mathrm{~Hz}$ & B.3 & & $2.0 \mathrm{~Hz}$ & C. 3 & & $2.0 \mathrm{~Hz}$ \\
\hline A.4 & & $2.2 \mathrm{~Hz}$ & B. 4 & & $2.2 \mathrm{~Hz}$ & C. 4 & & $2.2 \mathrm{~Hz}$ \\
\hline A.5 & & $2.4 \mathrm{~Hz}$ & B.5 & & $2.4 \mathrm{~Hz}$ & C.5 & & $2.4 \mathrm{~Hz}$ \\
\hline
\end{tabular}

Table 3. The first 20 frequencies of the structure.

\begin{tabular}{||c|c|c|c||}
\hline Mode & Frequency(Hz) & Mode & Frequency $(\mathrm{Hz})$ \\
\hline 1 & 2.366 & 11 & 5.554 \\
\hline 2 & 2.484 & 12 & 5.687 \\
\hline 3 & 2.971 & 13 & 5.724 \\
\hline 4 & 3.765 & 14 & 5.828 \\
\hline 5 & 3.999 & 15 & 5.920 \\
\hline 6 & 4.552 & 16 & 6.171 \\
\hline 7 & 4.825 & 17 & 6.231 \\
\hline 8 & 5.048 & 18 & 6.499 \\
\hline 9 & 5.306 & 19 & 6.607 \\
\hline 10 & 5.538 & 20 & 6.728 \\
\hline
\end{tabular}

frequency. Thus, the most unfavorable condition was when the load frequency is close to the nature frequency of the structure, which needs to be avoided.

The acceleration responses of the same excitation frequency were combined by SRSS, and the results are shown in Table 4. As revealed in Table 4, when walking loads with the excitation frequency of 2.2 and $2.4 \mathrm{~Hz}$ were added to the bowl and corridor, the acceleration responses will exceed the limit value of ISO2631-2, so vibration control was needed. Additionally, when comparing the acceleration responses of the same case at different excitation frequency, it can be found that for the bowl, the maximum acceleration was at the walking load of $2.4 \mathrm{~Hz}$, while for the corridor, the peak may occur at the walking load of $2.2 \mathrm{~Hz}$. The reason for this lies in the modal analysis shown in Table 3. As stated in section 3.2, the first mode of the structure is the vertical vibration of the bowl and the $16^{\text {th }}, 19^{\text {th }}$ mode are the vertical vibration of the corridor. The first mode frequency is $2.366 \mathrm{~Hz}$, close to $2.4 \mathrm{~Hz}$ and the $19^{\text {th }}$ mode frequency is $6.607 \mathrm{~Hz}$, close to $6.6 \mathrm{~Hz}$. Thus, the conclusion was that the load of the same or multiples of the mode frequency may induce the most unfavorable condition of the mode, which is consistent with the conclusion acquired from Figure 5 and 6.

\subsection{Dynamic Calculation of the Structure with TMDs}

\subsubsection{The Determination of the Installation Site of TMDs}

Based on the modal analysis and the dynamic calculation of the structure without TMD, it was necessary to use MTMD to implement multimode control. According to the basic principles of TMDs, the damping effect can achieve the best when TMDs are set at the maximum modal displacement. Thus, based on the first order mode shown in Figure 4, the TMDs were set along the external rim of the bowl. The sketch map of the MTMD installation site is shown in Figure 7. For the bowl, 8 TMDs of type A are placed along the external rim, where four TMDs in the middle and two at each side.

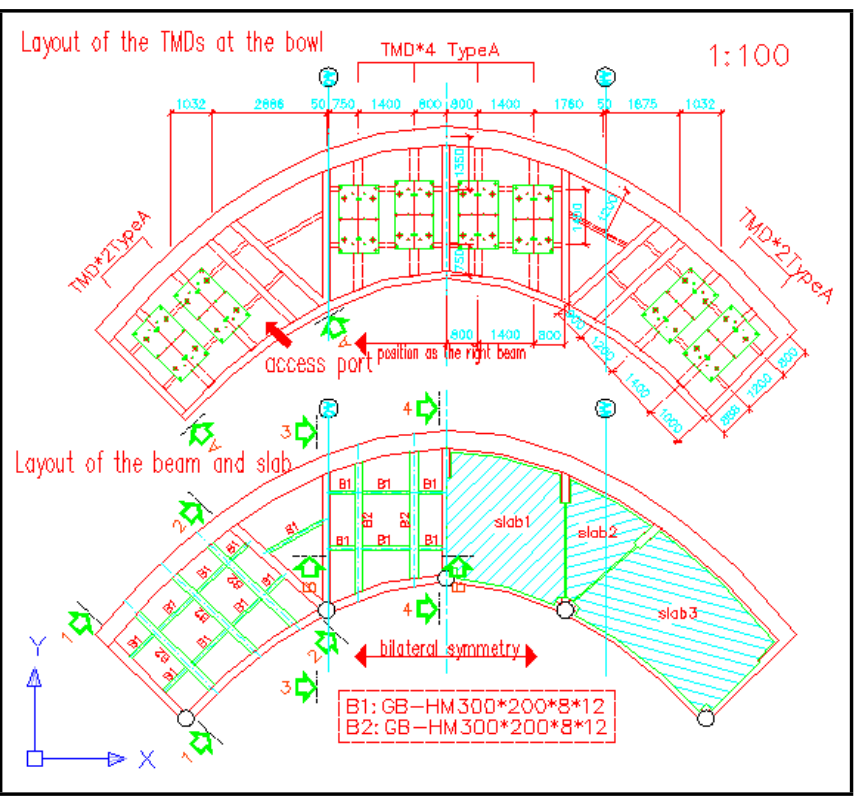

Figure 7. The sketch map of the MTMD installation site.

\subsubsection{The Determination of the Technical Parameters of TMDs}

By adjusting the mass ratio, frequency ratio and damping ratio of the TMDs with the main structure, the TMD system can absorb more energy, and then mitigate the vibration response of the main structure. The mass of the MTMD was set initially based on the mass participation of the controlled mode and engineering experience of GERB. The frequency of the MTMD was determined by the frequency of the controlled mode. The Den-Hartog formula is used to optimize the stiffness factor and damping factor: ${ }^{23}$

$$
\delta_{o p t}=\frac{1}{1+\mu}, \zeta_{o p t}=\sqrt{\frac{3 \mu}{8(1+\mu)}} ;
$$

$\mu$ denoted the mass ratio of the TMDs system, $\delta_{\text {opt }}$ denoted the optimal frequency ratio, and $\zeta_{o p t}$ denoted the optimal damping ratio.

After comparing the damping effect of different numbers of TMDs, the scheme of 8 type A TMDs and 2 type B TMDs was finalized.

The determined parameters of MTMD are shown in Table 5. Based on the modal analysis, the TMDs of type A were aimed at controlling the first mode of the structure, which was the vertical vibration of the bowl, while TMDs of type B weare aimed at controlling the $16^{\text {th }}, 19^{\text {th }}$ mode, which was the vertical vibration of the corridor. Notes: 1 . All the parameters are of the single TMD. 2. The frequency in the table is the central controlled frequency of TMD, and TMD works in frequencies around the controlled frequency. 
Table 4. The combination value of the conditions without TMD.

\begin{tabular}{|c|c|c|c|c|c|c|c|}
\hline \multicolumn{8}{|c|}{ The bowl } \\
\hline Condition & $\begin{array}{c}\text { Acceleration } \\
\left(\mathrm{m} / \mathrm{s}^{2}\right)\end{array}$ & Condition & $\begin{array}{c}\text { Acceleration } \\
\left(\mathrm{m} / \mathrm{s}^{2}\right)\end{array}$ & Condition & $\begin{array}{c}\text { Acceleration } \\
\left(\mathrm{m} / \mathrm{s}^{2}\right)\end{array}$ & $\begin{array}{c}\text { Excitation } \\
\text { frequency }(\mathrm{Hz})\end{array}$ & $\begin{array}{l}\text { Combination } \\
\text { value }\left(\mathrm{m} / \mathrm{s}^{2}\right)\end{array}$ \\
\hline A. 1 & 0.074 & B. 1 & 0.049 & C. 1 & 0.020 & 1.6 & 0.091 \\
\hline A. 2 & 0.077 & B. 2 & 0.050 & C. 2 & 0.020 & 1.8 & 0.094 \\
\hline A.3 & 0.087 & B.3 & 0.064 & C.3 & 0.022 & 2.0 & 0.110 \\
\hline A. 4 & 0.132 & B.4 & 0.097 & C. 4 & 0.028 & 2.2 & 0.166 \\
\hline A. 5 & 0.259 & B.5 & 0.175 & C. 5 & 0.043 & 2.4 & 0.316 \\
\hline \multicolumn{8}{|c|}{ The corridor } \\
\hline Condition & $\begin{array}{c}\text { Acceleration } \\
\left(\mathrm{m} / \mathrm{s}^{2}\right)\end{array}$ & Condition & $\begin{array}{c}\text { Acceleration } \\
\left(\mathrm{m} / \mathrm{s}^{2}\right)\end{array}$ & Condition & $\begin{array}{c}\text { Acceleration } \\
\left(\mathrm{m} / \mathrm{s}^{2}\right)\end{array}$ & $\begin{array}{c}\text { Excitation } \\
\text { frequency }(\mathrm{Hz})\end{array}$ & $\begin{array}{l}\text { Combination } \\
\text { value }\left(\mathrm{m} / \mathrm{s}^{2}\right)\end{array}$ \\
\hline A. 1 & 0.057 & B.1 & 0.088 & C. 1 & 0.017 & 1.6 & 0.106 \\
\hline A. 2 & 0.055 & B. 2 & 0.082 & C. 2 & 0.020 & 1.8 & 0.101 \\
\hline A.3 & 0.078 & B.3 & 0.101 & C.3 & 0.022 & 2.0 & 0.129 \\
\hline A. 4 & 0.090 & B.4 & 0.153 & C. 4 & 0.033 & 2.2 & 0.181 \\
\hline A.5 & 0.173 & B.5 & 0.145 & C.5 & 0.026 & 2.4 & 0.227 \\
\hline
\end{tabular}

Table 5. The parameters of MTMD.

\begin{tabular}{|c|c|c|c|c|c|c|c|c|c|}
\hline Type & Number & $\begin{array}{c}\text { Installation } \\
\text { position }\end{array}$ & $\begin{array}{c}\text { Mode } \\
\text { controlled }\end{array}$ & $\begin{array}{c}\text { Frequency } \\
\text { controlled }(\mathrm{Hz})\end{array}$ & $\begin{array}{c}\text { Mass } \\
(\text { ton })\end{array}$ & $\begin{array}{c}\text { Stiffness } \\
(\mathrm{kN} / \mathrm{m})\end{array}$ & $\begin{array}{c}\text { Optimized } \\
\text { frequency }(\mathrm{Hz})\end{array}$ & $\begin{array}{c}\text { Damping } \\
\text { factor }(\mathrm{kN} \cdot \mathrm{s} / \mathrm{m})\end{array}$ & $\begin{array}{c}\text { Total mass } \\
(\text { ton })\end{array}$ \\
\hline A & 8 & Bowl & 1 & 2.36 & 3 & 625 & 2.30 & 8.9 & 24 \\
\hline B & 2 & Corridor & 18 & 6.50 & 1 & 1590 & 6.35 & 7.3 \\
\hline
\end{tabular}

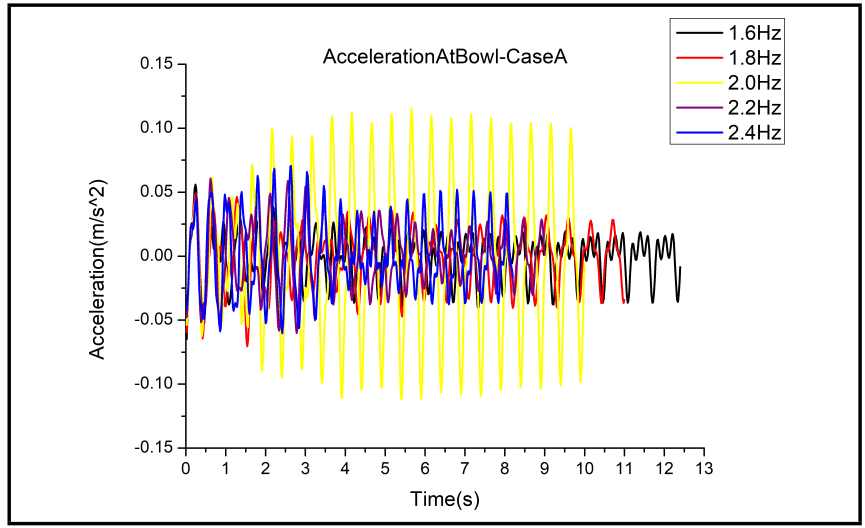

Figure 8. The acceleration response at bowl with TMD (Case A).

\subsubsection{The MTMD Reduction Calculation}

The structure with MTMD wais analyszed to verify the damping effect of the MTMD. The computation model and the pedestrian loads remained unchanged as the analysis without TMD, and the joint with mass was used to simulate the mass of the TMD. The built-in viscoelastic damper in midas Gen was applied to connect the joint with mass and the node where TMD was placed. The kelvin model can simulate the stiffness and damping characteristics of the TMD.

The acceleration responses at bowl and corridor with TMDs of Case A are shown in Figures 8 and 9, separately. From Figure 8, it is obvious that the acceleration response of $2.0 \mathrm{~Hz}$ was larger than the other conditions. Thus, it can be inferred that the natural frequency of the structure with TMDs turned to about $2.0 \mathrm{~Hz}$, which proved the fact TMDs can change the natural frequency of the original structure effectively.

The acceleration responses of the same excitation frequency were combined by SRSS, and the results are shown in Table 6. As revealed in Table 6, the acceleration responses of all conditions can meet the requirement of ISO2631-2, which lead to the conclusion that TMD control was an effective way to reduce human-induced vibration.

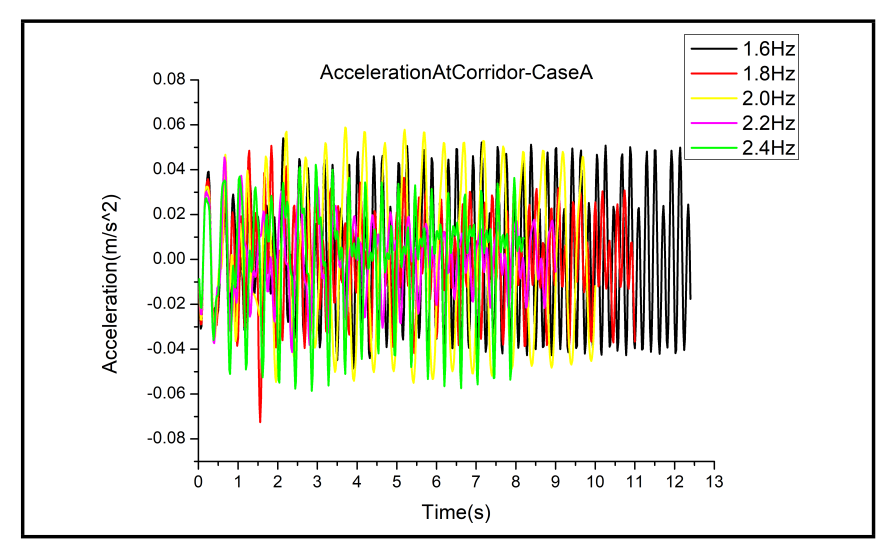

Figure 9. The acceleration response at corridor with TMD (Case A).

\subsection{Comparison}

The combination values of the five frequencies without and with TMD are compared in Figure 10 and 11. Before the installation of TMDs, the walking-induced acceleration was greater than the limit value in ISO under some conditions, which may cause serious serviceability problems. After the TMDs were set, the acceleration response met the demand of ISO perfectly. The installation of TMDs changed the condition where peak value occur. Taking Figure 10 for example, the maximum acceleration was at the case of $2.4 \mathrm{~Hz}$ without TMDs, while after TMDs were installed, the peak value occurred at the case of 2.0 Hz. This shows that TMDs changed the natural frequency of the original structure. Additionally, it was obvious that the attenuation rate of the TMDs at different cases were various. It can be concluded that the damping effect of the TMDs was closely concerned with the excitation frequency.

Through analysis and comparison, it was revealed that TMDs can reduce the structure vertical vibration effectively, with the attenuation rate of more than $50 \%$. The acceleration responses without TMDs were considerably larger than the limited value, according to ISO2631-2. After the installation of the TMDs, the acceleration responses were lower than $0.15 \mathrm{~m} / \mathrm{s}^{2}$, which can meet the need of $1 \mathrm{SO} 2631-2$. 
Table 6. The combination value of the conditions with TMD.

\begin{tabular}{|c|c|c|c|c|c|c|c|}
\hline \multicolumn{8}{|c|}{ The bowl } \\
\hline Condition & $\begin{array}{c}\text { Acceleration } \\
\left(\mathrm{m} / \mathrm{s}^{2}\right)\end{array}$ & Condition & $\begin{array}{c}\text { Acceleration } \\
\left(\mathrm{m} / \mathrm{s}^{2}\right)\end{array}$ & Condition & $\begin{array}{l}\text { Acceleration } \\
\left(\mathrm{m} / \mathrm{s}^{2}\right)\end{array}$ & $\begin{array}{c}\text { Excitation } \\
\text { frequency }(\mathrm{Hz})\end{array}$ & $\begin{array}{l}\text { Combination } \\
\text { value }\left(\mathrm{m} / \mathrm{s}^{2}\right)\end{array}$ \\
\hline A.1 & 0.065 & B.1 & 0.046 & C.1 & 0.014 & 1.6 & 0.074 \\
\hline A. 2 & 0.070 & B. 2 & 0.066 & C. 2 & 0.015 & 1.8 & 0.081 \\
\hline A. 3 & 0.115 & B.3 & 0.084 & C. 3 & 0.026 & 2.0 & 0.145 \\
\hline A. 4 & 0.061 & B. 4 & 0.055 & C. 4 & 0.015 & 2.2 & 0.083 \\
\hline A.5 & 0.070 & B.5 & 0.047 & C.5 & 0.014 & 2.4 & 0.085 \\
\hline \multicolumn{8}{|c|}{ The corridor } \\
\hline Condition & $\begin{array}{l}\text { Acceleration } \\
\left(\mathrm{m} / \mathrm{s}^{2}\right)\end{array}$ & Condition & $\begin{array}{l}\text { Acceleration } \\
\left(\mathrm{m} / \mathrm{s}^{2}\right)\end{array}$ & Condition & $\begin{array}{l}\text { Acceleration } \\
\left(\mathrm{m} / \mathrm{s}^{2}\right)\end{array}$ & $\begin{array}{c}\text { Excitation } \\
\text { frequency }(\mathrm{Hz})\end{array}$ & $\begin{array}{l}\text { Combination } \\
\text { value }\left(\mathrm{m} / \mathrm{s}^{2}\right)\end{array}$ \\
\hline A.1 & 0.054 & B.1 & 0.076 & C. 1 & 0.014 & 1.6 & 0.076 \\
\hline A. 2 & 0.073 & B. 2 & 0.070 & C. 2 & 0.021 & 1.8 & 0.073 \\
\hline A.3 & 0.059 & B.3 & 0.063 & C. 3 & 0.016 & 2.0 & 0.086 \\
\hline A. 4 & 0.045 & B. 4 & 0.057 & C. 4 & 0.013 & 2.2 & 0.062 \\
\hline A. 5 & 0.059 & B.5 & 0.098 & C. 5 & 0.016 & 2.4 & 0.116 \\
\hline
\end{tabular}

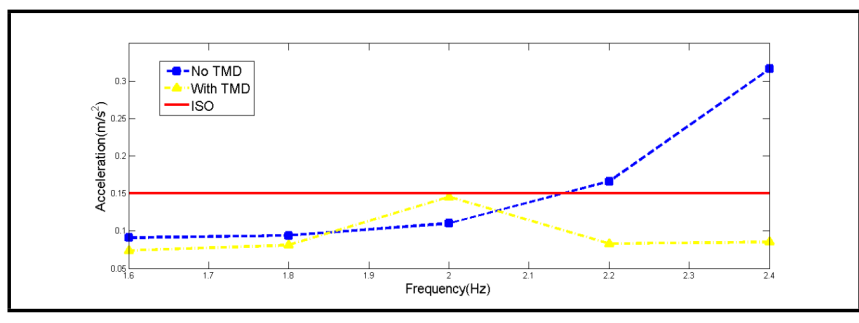

Figure 10. The comparison of acceleration response without and with TMD at bowl.

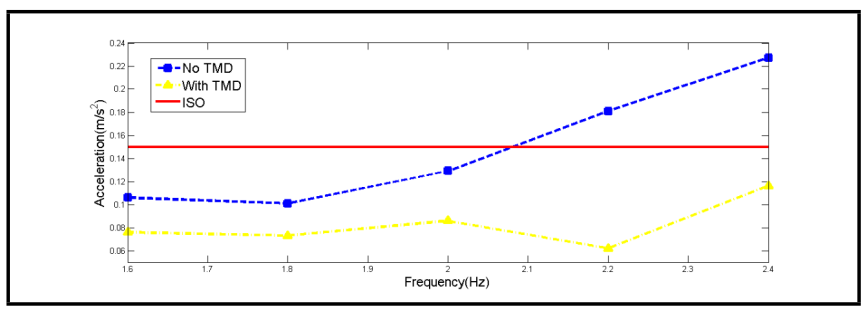

Figure 11. The comparison of acceleration response without and with TMD at corridor.

\section{FIELD-TESTS}

There are often some differences between the theoretical calculation and field measurement, so field tests and modification were necessary, as is shown in Figure 12. Several acceleration sensors and a set of data collection system were applied in field tests. After the museum was structurally completed, field tests were performed, which indicated that the structure has a natural frequency of $2.7 \mathrm{~Hz}$, as is shown in Figure 13.

As stated in section 2.2, the operation principle of TMD is to make sure that the vibration of the structure can lead to the resonance of the TMD. Thus, the natural frequency of the TMDs should be controlled near the natural frequency of the practical structure. The TMDs were set to $2.36 \mathrm{~Hz}$ when installed, so springs were added between the TMD and the floor to increase the stiffness of the TMDs, in order to adjust the frequency of the TMDs to $2.7 \mathrm{~Hz}$.

Then, the field-tests of the structure without TMD were performed. The walking load of six people jumping at the bowl was added at the structure without TMD. The acceleration response is shown in Figure 14. It can be seen from the acceleration response that the maximum acceleration reaches $0.32 \mathrm{~m} / \mathrm{s}^{2}$, which exceeded the limit value in ISO2631-2. During the beginning 20 seconds, the acceleration has always been

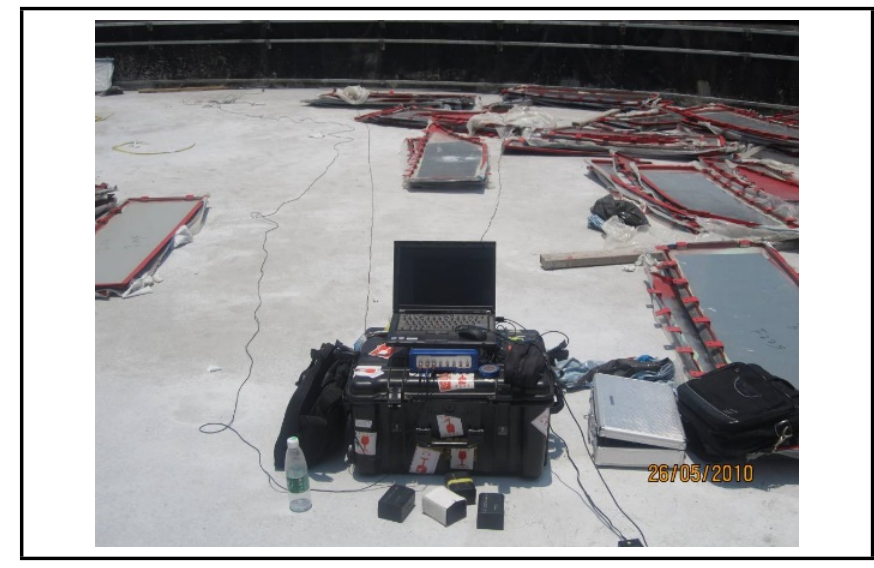

Figure 12. The field tests of the structure with and without TMDs.
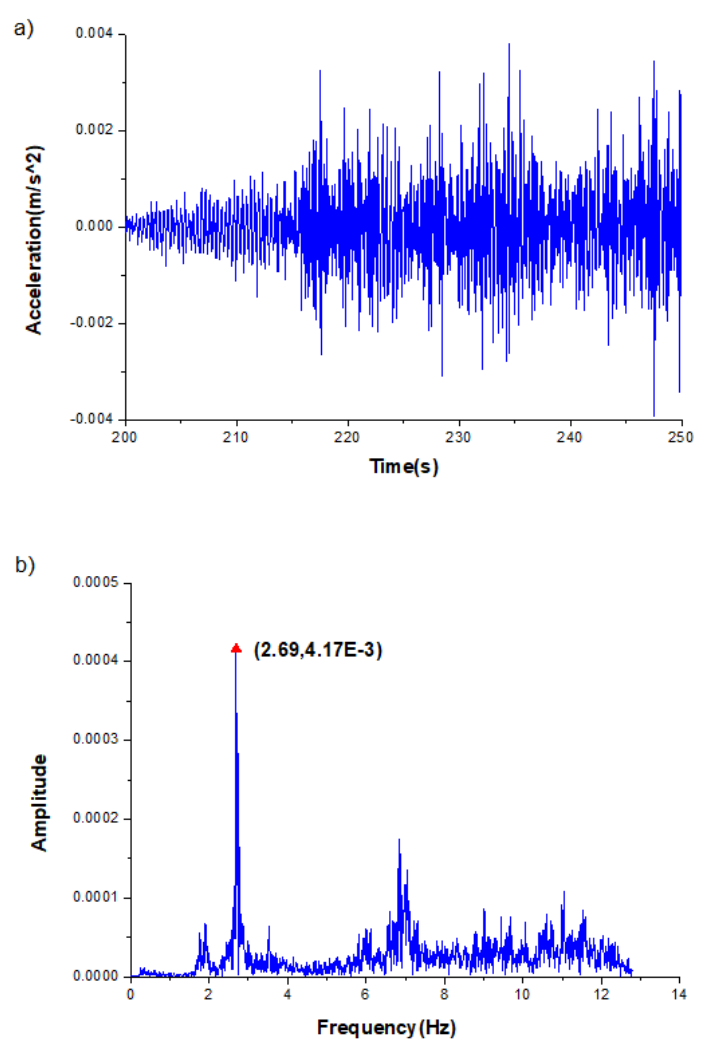

Figure 13. (a)Time and (b)frequency response of acceleration of the original structure under natural excitation. 


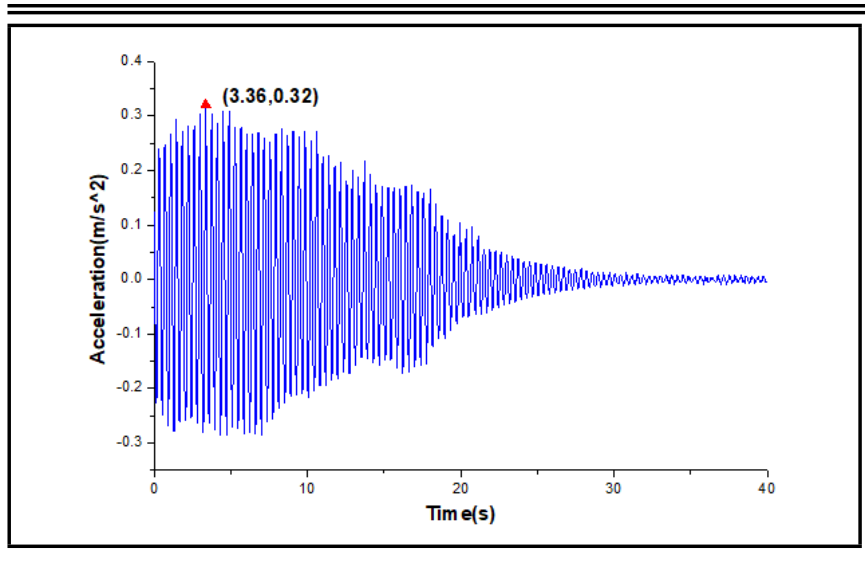

Figure 14. The acceleration response of the structure without TMD.

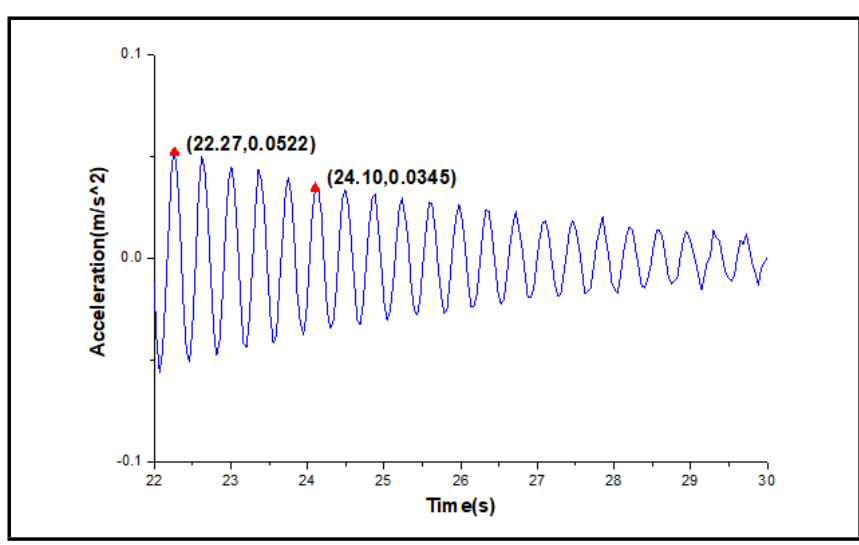

Figure 15. The free decay of the structure without TMD.

over $0.15 \mathrm{~m} / \mathrm{s}^{2}$, which may easily cause serviceability problems.

The free decay part of the time history is cut out to calculate the damping ratio of the structure without TMD. As is shown in Figure 15, two peak points are chosen to calculate the damping ratio. The damping ratio of the structure without TMD was $1.32 \%$.

Lastly, the same walking load was added to the structure with TMD. As is shown in Figure 16, the peak acceleration is lower than $0.1 \mathrm{~m} / \mathrm{s}^{2}$, which meets the demand of ISO26312. The same method was used to calculate the damping ratio of the structure with TMD. The calculated damping ratio was $7.58 \%$. The damping ratio increased with the damping effect of TMDs, which proves the conclusion from equation (1) that TMDs contribute to the damping matrix of the structure and enhance the energy dissipation capacity of the main structure.

The comparisons of the field tests result without and with TMD are shown in Figure 17 and Table 7. From Figure 17 and Table 7 above, the conclusions can be drawn from the fieldtests: (1) The vertical vibration induced by human walking was attenuated by $70 \%$, after the installation of the TMDs; (2) TMDs had changed the natural frequency of the original structure; (3) The damping ratio of the structure had a significant increase with the assistance of TMDs.

Table 7. The comparison of the field tests results.

\begin{tabular}{|c|c|c|c|}
\hline Condition & $\begin{array}{c}\text { Peak } \\
\text { acceleration (gal) }\end{array}$ & $\begin{array}{c}\text { Frequency } \\
(\mathrm{Hz})\end{array}$ & $\begin{array}{c}\text { Damping } \\
\text { ratio (\%) }\end{array}$ \\
\hline Without TMD & 32 & 2.71 & 1.32 \\
\hline With TMD & 9.7 & $2.25 / 2.80$ & 7.58 \\
\hline
\end{tabular}

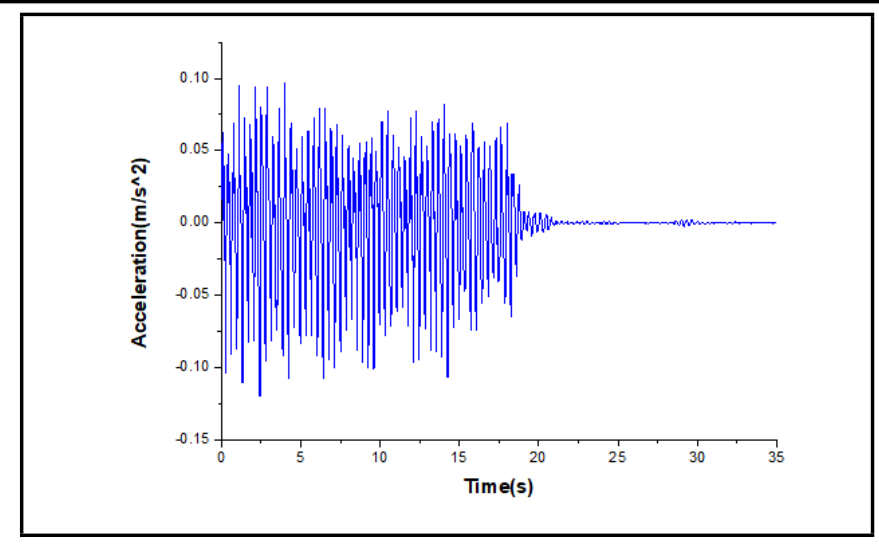

Figure 16. The acceleration response of the structure with TMD.

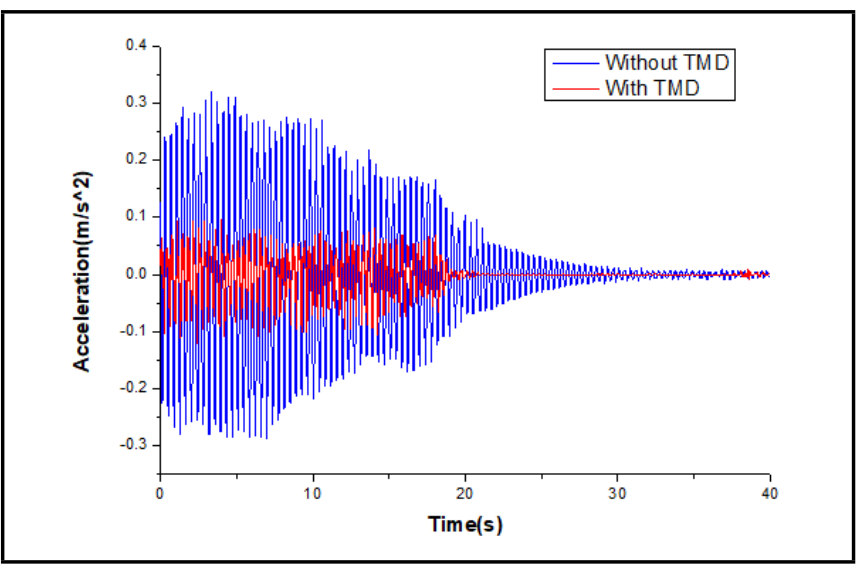

Figure 17. The comparison of the acceleration of the structure without and with TMD.

\section{CONCLUDING REMARKS}

An analysis using midas Gen and fielld-tests of human walking induced vibration reduction with TMDs in the Guangzhou Asian Games Comprehensive Museum is presented in this study. The damping effect of the TMDs is revealed by comparing the acceleration response with and without TMD. The main conclusions can be listed as follows:

1. Long-span structures have a low natural frequency. Obvious resonance will occur when the walking frequency is very close to the natural frequency of the structure, which is the most unfavorable condition. The vibration caused by human walking may induce serviceability even safety problems, which needs to be controlled.

2. Long-span structures have intense modes, a system of multiple TMDs has a better damping effect than a single TMD. TMDs can reduce the human walking induced vibration effectively, especially for long-span structures under walking load, which can be applied in many other projects.

3. TMD is a frequency-sensitive element, so the parameters of the TMDs need to be carefully determined. The optimization and comparison need to be conducted to improve the damping effect of the TMDs. In order to ensure the effectiveness of the TMDs in the practical structure, field tests and modification are necessary before TMDs are installed. 
4. The damping effect of TMDs concerns not only the natural frequency of the structure, but also the external excitation frequency. When the external excitation frequency is away from the working frequency of the TMDs, the damping effect can be sharply decreased. Thus, improvements on enhancing the robustness need to be studied for better application of the TMD in vibration reduction.

\section{ACKNOWLEDGEMENTS}

This study was financially supported by the Program of Chang Jiang Scholars of Ministry of Education, the National Science Fund for Distinguished Young Scholars with granted number 51625803, the Tencent Foundation through the XPLORER, National Natural Science Foundation of China with granted number 11572088, the Jiangsu Province International Cooperation Project with granted number BZ2018058, the Program for Jiangsu Province 333 Talents, the Priority Academic Program Development of Jiangsu Higher Education Institutions with granted number CE02-1-47, Research and Innovation Project for College Graduates of Jiangsu Province with granted number KYLX15 0088, KYLX 0155 and KYLX16 0247. These supports are gratefully acknowledged.

\section{REFERENCES}

1 Figueiredo, F.P., Da Silva, J.G.S, and De Lima, L.R.O.A parametric study of composite footbridges under pedestrian walking loads, Engineering Structures, 30, 605-615, (2008). https://dx.doi.org/10.1016/j.engstruct.2007.04.021

2 Wood H. Some notes of vibrations in structures, The Journal of Royal Institute of British Architects, 55(12), 553-555, (1948).

3 Zivanovic, S., Pavic, A., and Reynolds, P. Vibration serviceability of footbridges under human-induced excitation: a literature review, Journal of Sound and Vibration, 279(1-2), 1-74, (2005). https://dx.doi.org/10.1016/j.jsv.2004.01.019

4 Ellingwood, B. and Tallin, A. Structural serviceability: floor vibrations, Journal of Structural Engineering, 110(2), 401-418, (1984). https://dx.doi.org/10.1061/(ASCE)07339445(1984)110:2(401)

5 Ebrahimpour, A. and Sack, R. L. A review of vibration serviceability criteria for floor structures, $\quad \mathbf{8 3}(28-30), \quad 2488-2494, \quad$ (2005). https://dx.doi.org/10.1016/j.compstruc.2005.03.023

6 British Standard (BS). BS5400-2:2006. Steel, concrete and composite bridges-part 2: specification for loads, British Standard (BS): London, British Standard Institution, (2006).

7 Pretlove, J and Rainer, H. Human response to vibrations, Vibration Problems in Structures: Practical Guidelines. (1995).

8 International Organization for Standardization. ISO 26312:2003, Mechanical vibration and shock-evaluation of human exposure to whole-body vibration-part 2: vibration in buildings ( $1 \mathrm{~Hz}$ to $80 \mathrm{~Hz}$ ), International Organization for Standardization, Geneva, Switzerland, (2003).
9 He, X.H, Yan, W.M, and Zhang, A.L. Dynamic interaction between human and beam-slab structures under human walking excitation, Journal of Vibration and Shock, 27(10), 130-133, (2008).

10 Williams, S. and Waldron, P. Evaluation of methods for predicting occupant-induced vibrations in concrete floors, Structural Engineer, 12(4), 34-39, 1994.

11 Sun, L.M. and Yan, H.F. Human walking induced footbridge vibration and its serviceability design, Journal of Tongji University (Natural science), 32(8), 996-999, (2004).

$12 \mathrm{Xu}, \mathrm{Z}$. D., Xu, Ch., Hu, J. Equivalent fractional Kelvin model and experimental study on viscoelastic damper. Journal of Vibration and Control, 21(13), 2536-2552 (2015).

$13 \mathrm{Xu}$, Z.D., Wang, S. A., Xu, Ch. Experimental and numerical study on long-span reticulate structure with multidimensional high-damping earthquake isolation devices, Journal of Sound and Vibration, 333(14): 3044-3057 (2014).

14 International Organization for Standardization. ISO 263111997:2003. Mechanical vibration and shock evaluation of human exposure to whole-body vibration-part 1: General Requirements, International Organization for Standardization, Geneva: Switzerland, (2003).

15 Da Silva, J.G.S. An evaluation of the dynamical performance of composite slabs, Computers and Structures.

16 Setareh, M., Ritchey, K., and Baxter, J. Pendulum tuned mass dampers for floor vibration control, Journal of Performance of Constructed Facilities, 20(1), 64-69, (2006). https://dx.doi.org/10.1061/(ASCE)08873828(2006)20:1(64)

17 Wheeler, J. Prediction and control of pedestrian-induced vibration in footbridges, Journal of the Structural Division, 108(9), 2045-2065, (1982).

18 Dai, J., Xu, Z. D., Gai, P. P., Li, H. W. Effect of Frequency Dependence of Large Mass Ratio Viscoelastic Tuned Mass Damper on Seismic Performance of Structures. Soil Dynamics and Earthquake Engineering, (2019).

19 CJJ 69-95:1996. Technical specifications of urban pedestrian overcrossing and underpass, Beijing: China Building Press, (1996).

$20 \mathrm{Xu}$, Y.L., Kwok, K.C.S, and Samali, B. The effect of tuned mass dampers and liquid dampers on cross-wind response of tall/slender structures, Journal of Wind Engineering and Industrial Aerodynamics, (1992). https://dx.doi.org/10.1016/0167-6105(92)90519-G

21 Wanami, K.I. and Scto, K. Optimal design of dual tuned mass dampers and their effectiveness, Proc. $\operatorname{JSME}(C), \mathbf{5 0}$, 44-52, (1984).

22 Clark, A.J. Multiple passive tuned mass damper for reducing earthquake induced building motion, Proc. 9th World Conf. on Earthquake Engrg, 5, 283-290, (1988).

23 Den Hartog, J.P. Mechanical vibrations, 4nd ed. New York: McGraw-Hill, 215-220, (1956). 